The Effect of Storytelling at School on Children's Oral and Written Language Abilities, and Self-Perception

Catherine Z. Wright \& Sandra Dunsmuir

Educational Psychology Group, Division of Psychology and Language Sciences, University College London, 26 Bedford Way, London, WC1H 0AP, UK. 


\title{
The Effect of Storytelling at School on Children's Oral and Written Language Abilities, and Self-Perception
}

\begin{abstract}
This study explored whether being told stories by a teacher in school four days a week for ten weeks would lead to improvements in six and seven year old children's oral language, written language and self-perception, and whether these improvements would be greater than those experienced by an active comparison group who were read the same stories from books, and a comparison group who continued with their usual classroom literacy practices. A quasiexperimental between-participants design was employed; 194 participants took part and classes, rather than participants, were randomly assigned to intervention conditions. Results showed that the storytelling group retold stories which were significantly longer and used a significantly wider range of vocabulary than both the group that were read the same stories and the comparison group, at post-test and three-month follow-up. The story-reading group scored significantly higher on an oral vocabulary test than the comparison group at follow-up.
\end{abstract}

Keywords: Oral language, storytelling, writing, self-perception, story reading 


\section{Introduction}

Storytelling. Storytelling involves recounting a story from memory or imagination, without a book. Storytelling occurs in almost every culture in the world and has been around for a long time, pre-dating writing; it is common to all human societies, and is used in the transmission of cultural heritage, having an important social and educational function (Mello, 2001). Different cultures have different approaches to oral storytelling. For example, oral storytelling in indigenous communities is often used as a way of teaching the community's values, rather than as a form of entertainment (Archibald, 2008). In the Sto:Io community in Canada, storytelling is used as a way to teach children about the land and their role within the community (Archibald, 2008). Similarly, in the Quechua community in Peru, storytelling is used as a way of teaching children about their culture and identity (Bolin, 2006). In contrast, the Hopi-Tewa community of Arizona use storytelling as a method of teaching children morals (Kroskrity, 2009). However, like many fields of research, storytelling has predominantly been formally researched in developed Western societies, a fact which is reflected in the overview of the literature on storytelling below.

Literature review on storytelling. A great deal of research has been conducted into the effect of story-reading on improving aspects of children's oral and written language development, such as their vocabulary (Baker et al., 2013; Brabham \& Lynch-Brown, 2002; Brett, Rothlein \& Hurley, 1996; Fien et al., 2011; Maynard, Pullen \& Coyne, 2010; Moore, Hammond \& Fetherston, 2014; Pullen, Tuckwiller, Konold, Maynard \& Coyne, 2010), but much less has looked at the effects of storytelling on language development. What limited research there is on storytelling has shown that storytelling has been associated with improvements in children's developing language and literacy skills, such as vocabulary (Maguire, 1985), fluency (Farrell \& Nessell, 1982), story comprehension (Palmer, Harshbarger, \& Koch, 2001), and story retelling. 
Isbell, Sobol, Lindauer and Lowrance (2004) compared the effect of storytelling and story-book reading on young children's (aged 3-5) language development and story comprehension. One group of children were told stories over a period of 12 weeks, and a second group were read the same stories from books. The storytelling group scored higher on a measure of story comprehension, and the story-book reading group scored higher on a measure of language complexity, showing that both of these interventions had a positive impact on children's language development (Isbell et al., 2004). Each group improved in aspects of language relating to the medium of the intervention they received: a finding noted in a number of other studies as well (Lonigan, Purpura, Wilson, Walker \& Clancy-Menchetti, 2013; Fisher \& Frey, 2017).

Similarly, Trostle and Hicks (1998) conducted a study showing that 7-11 year old children who were told stories scored significantly higher on measures of story comprehension and vocabulary than those who were read stories (Trostle \& Hicks, 1998). Also, Gallets (2005) compared the effect of storytelling versus story-reading on the language skills of children aged five to eight (Gallets, 2005). He found that both methods led to improvements on most measures, but those in the storytelling condition made bigger improvements than the other group on some measures, such as recalling information from the stories (Gallets, 2005). In addition, a study looking at the storytelling abilities of children with specific language impairments (SLIs) found that these children were able to tell stories involving better quality independent clauses, and the modifiers of these, when given verbal prompts while telling stories, than when given a wordless picture book to base the stories on (Epstein \& Phillips, 2009).

As technological advances have been made, storytelling has begun to be used in combination with these, to develop children's language skills. For example, one study explored using robots to tell stories to pre-school children, modelling narration skills and 
introducing new vocabulary to them, to see the effect on the children's language abilities (Kory \& Breazeal, 2014). Findings have not yet been reported as this is the start of a longitudinal study, but the researchers anticipate finding that if a robot adapts its language ability to match, or be greater than, the children's developing language ability then this will lead to improvements to the children's vocabulary and storytelling abilities as a result of interaction with the storytelling robot, to a greater extent than if the robot does not adapt during the intervention (Kory \& Breazeal, 2014). They suggest that using robots may be an effective way to support and develop young children's language skills (Kory \& Breazeal, 2014).

As well as a growing body of research into the positive effects of storytelling on children's development, there has been a burgeoning national awareness in the United Kingdom (UK) of the benefits of storytelling, and a move towards incorporating storytelling into education practices. For example, in February 2016, the Minister of State for School Standards in the UK gave a speech explaining the importance of storytelling for children's language development, as well as for expanding their imagination, and leading to the development of other skills, such as becoming competent readers, which in turn positively impacts on their later education (Gibb, 2016). In addition, the national initiative 'Talk for Writing' (DfE, 2008), made in collaboration with the storyteller Pie Corbett, is now used in many UK elementary schools (Corbett, 2007). This involves a class of children being told a story by their teacher from memory, and then beginning to learn the story themselves and taking part in a range of activities related to it (Corbett, 2007); however this intervention does not yet have a published evidence-base.

Summary. This research all suggests that storytelling can lead to a number of improvements to children's language skills, but more research may be needed to further explore these benefits. Therefore, the first aim of the current study was to replicate research 
findings showing improvements to children's oral language as a result of a storytelling intervention.

Theory and literature review of oral and written language development. Dockrell and Connelly's (2009) theory relating to the interconnection between the development of oral and written language is the main theory that informed this study. This theory suggests that children's knowledge of oral language helps to develop their written language when children are first learning to write (Dockrell \& Connelly, 2009).

This has been highlighted by evidence that children's writing quality is influenced by their oral language skills at a number of levels, such as the word, subword, and sentence level (Berninger, Mizokawa, Bragg, Cartwright, \& Yates, 1994), particularly in the early stages of writing (Shanahan, 2006), when there are many similarities between oral and written language expression, and children's written narratives have a very similar semantic structure to their oral narratives (Hidi \& Hildyard, 1983). Moreover, children who have higher levels of proficiency at speaking their first language, were found to have better writing abilities in their second language than those with less spoken proficiency in their first language (Cummins, 1991), suggesting that knowledge from speaking informs writing even across languages.

Also, children's oral vocabulary at the time of starting school is often a predictor of their later writing attainment (Dunsmuir \& Blatchford, 2004), and for children with Specific Language Impairments (SLIs), oral vocabulary has been found to significantly contribute to writing ability (Dockrell, Lindsay, Connolly, \& Mackie, 2007). In addition, research shows that children with SLIs often have constrained written language abilities (Dockrell \& Connelly, 2009), and poor oral language skills, such as limited oral vocabulary or poor oral narrative production, have been associated with difficulties in composing written text (Bishop \& Clarkson, 2003; Puranik, Lombardino, \& Altmann, 2007), highlighting the importance of 
oral language for developing written language. This could be due to a number of reasons, such as low language ability generally, or a specific difficulty relating to grammar, vocabulary or spelling, or greater cognitive demands placed on a child with poor oral language when attempting to write (Dockrell \& Connelly, 2009). For example, even though oral and written language involve many of the same abilities, such as lexical retrieval and formulating syntax, producing written language seems to require more cognitive effort and resources than producing oral language (Bourdin \& Fayol, 2000), and children find it harder to create a written narrative than a spoken one (Gillam \& Johnston, 1992).

Oral language. Young children's oral language almost always develops before their written language and all typically-developing children learn to speak at least one language during early childhood without needing any formal instruction (Crain \& Lillo-Martin, 1999); however, oral language then continues to develop alongside the development of written language during early and middle childhood (Semel, Wiig, \& Secord, 2003). Linguistic constructions seen in speech appear in writing about a year later (Loban, 1976), and the four main elements of oral and written language (speaking, listening, reading and writing) develop in overlapping stages, rather than discrete phases during this time (Berninger, 2000; Shanahan, 2006).

Written language. The process of writing involves using some 'talk knowledge' (Myhill, 2009). With some exceptions (such as forms of writing which are very similar to speech and vice versa), informal speech and formal writing are linguistically distinct (Myhill, 2009). For example, writing is usually more lexically dense and better integrated than speech (Czerniewska, 1992), containing complex and longer clauses and constructions (Chafe, 1982) and more passives than speech (O’Donnell, 1974). There is usually more repetition in speech, and more joining of clauses in writing (Perera, 1987). 
When children are learning to write they have to apply knowledge about the grammar of writing, as well as being able to think about how someone reading their writing might understand it ('reader-awareness') - this first skill usually develops before the second (Myhill, 2009). Therefore, inexperienced writers produce 'writer-based' writing (focussing on their own writer's perspective), whereas experienced writers produce 'reader-based' writing (as they become more aware of their audience and aim their writing at them; Flower, 1979). Initially, a child learning to write will scribe what comes to mind, and tend to rely on the conventions of spoken language when producing pieces of writing (Bereiter \& Scardamalia, 1982). As they develop their writing skills, they become aware of how their text will come across to the reader; the more similar a written form is to the spoken form, the easier it is for inexperienced writers to write it down (Bereiter \& Scardamalia, 1982). With age, children's oral and written language usually become more distinct; and they will begin to use more complex grammatical constructions in writing than they do in speech, and to use more constructions specific to spoken language when speaking. By age eight, most children's writing contains few informal oral constructions - they are not simply writing down what they might say, as they did when younger (Perera, 1986), but are using formal written conventions. Also, with age children attend less to the secretarial aspects of the writing process, as this becomes more automatic (Wray, 1994).

Summary. Given this inter-relationship between the development of oral and written language, there is reason to hypothesize that an oral storytelling intervention, shown to improve the oral language skills of young children (Isbell et al., 2004), may also lead to improvements in children's written language. This may be because generating a spoken and a written narrative both use language-related abilities (Cragg \& Nation, 2006), and therefore children who are proficient at doing one, are likely to be good at doing the other. Thus, an intervention, such as a storytelling intervention where children are told stories orally, may 
provide young children with frameworks from oral language that also fit in with writing conventions, allowing them to effectively structure and develop their writing skills. Therefore, the second aim of the current study was to explore whether a storytelling intervention, which may lead to improvements to children's oral language, can also lead to improvements to children's written language.

Storytelling, school connectedness and self-perception. A mediating factor on the development of children's oral and written language is the way children experience their learning environment. If children feel comfortable and happy at school they are likely to be able to focus and produce higher quality work, leading to them developing better oral and written language skills. School connectedness (i.e. children's belief that people in their school care about both their learning and their wellbeing) has been associated with: greater likelihood of academic success (Blum, 2005) and a reduction in fighting and classroom disruption (Freiberg, 1989). This suggests that school connectedness is an important factor when considering language and literacy interventions and engagement. It is argued that interventions which promote children's belief that adults and peers in their school care about, and are invested in, their academic progress are likely to be effective in improving engagement and learning. Interventions leading to children feeling more connected to those around them may also lead to the development of more positive concepts about themselves and their abilities in certain domains, as children's self-perception is created by their experiences and understanding of their surroundings and their own judgements of their behaviour, as well as by judgements made by people who are important to them (Shavelson, Hubner \& Stanton, 1976). School connectedness has been associated with children reporting higher levels of emotional well-being (Resnick, Harris \& Shew, 1997) and self-esteem (King, Vidourek, Davis \& McClellan, 2002), suggesting an association between school connectedness and self-perception. 
Storytelling at school may be a way of increasing children's school connectedness and, through that, their self-perception. For example, it has been postulated that stories are a way of transmitting social knowledge and practices, through sharing personal understanding and experiences with others (Egan, 1995). Stories are also used to develop self-perception through creating and developing personal narratives by ordering and recounting experiences (Polkinghorne, 1991). Many traditional stories, such as fables and folk tales, are used to teach morals and ethical perspectives, strengthening the social knowledge of the culture they represent (Mello, 2001). In early research in this area, children who were told folk stories formed connections between events which happened to characters in the stories and events occurring in their own lives (Applebee, 1978; Favat, 1977), illustrating the social connectedness generated by storytelling.

More recent research has found similar results. For example, Mello (2001) told children a number of stories and then discussed these with them afterwards. He found that the process of storytelling, as well as the stories' content, had a positive effect on the children's feelings of empathy, interest, and relationships with others (Mello, 2001). The stories elicited responses of sympathy towards the various characters and situations described, and, through discussion, allowed the children to think in greater depth about the social aspects of their world (Mello, 2001). Moreover, Egan (1997) suggests that storytelling stimulates children's active engagement in the story through application of emotional intelligence and cognitive abilities (Egan, 1997). This suggests that listening to a story is a social, as well as an emotionally engaging and interactive, shared experience, likely to be associated with children's feelings of connectedness with those around them, as well as positively impacting on the way they perceive themselves.

Thus, storytelling has been described as fundamental to the development of healthy social relationships (Pranis, 2001), helping children feel connected to their school community, 
increasing pro-social behaviour, and decreasing anti-social behaviour (McNeely, Nonnemaker, \& Blum, 2002). Storytelling is likely to be generally helpful in supporting students to create inclusive spaces for themselves. Towards this end, storytelling could become part of creating a rich, language learning environment across the curriculum and throughout the day in schools to support children's developing language skills (Barnes, 1990), rather than being an isolated activity for developing children's language skills. Bruner (1986) argued that humans are hard-wired to absorb, interpret, transform and retell stories as a way to make sense of the world (Bruner, 1986). The ability to apply tenses (to place in time) to the conditional clause ('what if?') has allowed for imagination and the 'stuff of thought' to be the drivers for the 'story-telling instinct' (Pinker, 1990), which is perhaps the most basic and fundamental learning tool available when working with children. Limited evidence has been conducted in this area, but Myers (1990) found that children were more engaged and fidgeted less when they were told stories than when they were read stories from books (Myers, 1990), indicating a higher level of engagement.

Summary. All of this research suggests that if storytelling is conducted at school, it could promote emotional closeness and empathy between the children in the class listening to the story, and between the children and the teacher telling the story, increasing feelings of school connectedness. This, in turn, is likely to improve children's perception of their own abilities in different domains at school. Therefore, the third aim of the current study was to explore the impact of a storytelling intervention on children's self-perception at school.

Aims. To summarise, the three aims of the current study were:

1) To replicate research findings showing improvements to children's oral language as a result of a storytelling intervention. 
2) To explore whether a storytelling intervention, which may lead to improvements to children's oral language, can also lead to improvements to children's written language.

3) To explore the impact of a storytelling intervention on children's self-perception at school.

\section{Method}

Participants. Eight classes of children (aged 6-7) from six inner-city schools from the same urban area participated in the study (two two-class entry schools, and four one-class entry schools, with between 21 and 30 children in each class), with a total of 194 children participating (105 boys; 89 girls). A quasi-experimental between-participants design was used, meaning that classes, rather than individual children, were randomly assigned to conditions. The eight classes of children were randomly assigned to one of three groups: the storytelling group (three classes; 62 participants); the story-reading group (three classes; 79 participants); and the comparison group (two classes; 53 participants).

None of the children participating in this study had any previous or concurrent experience of taking part in a storytelling intervention, although some of the teachers delivering the interventions reported telling their class stories orally from time to time. The comparison group had fewer participants than the other two groups as this group consisted of only two classes of children, rather than three. There was variance between the percentages of children from different ethnic backgrounds in the three groups. However, a more relevant factor here was the number of participants learning English as an Additional Language (EAL) as this study was exploring children's oral and written language abilities, and the three intervention groups were comparable in terms of participant characteristics relating to this factor, as well as for numbers of children of each gender, numbers of children with Special Educational Needs (SEN), numbers of children with pupil premium eligibility (an index of 
social deprivation), and age of the children at the start of the intervention. Independentsamples t-tests were carried out to see if there were any significant differences in the numbers of children with each of these characteristics in the different intervention groups. These ttests showed that there was no significant difference in any of these variables between the storytelling group and the story-reading group, or between the storytelling group and the comparison group. However, there was a significant difference in the number of WhiteBritish children between the comparison group $(M=0.92, S D=0.267)$ and the story-reading group $(M=0.80, S D=0.404) ; t(130)=2.01, p=0.46)$.

Procedure. The intervention was run for ten weeks. The storytelling group were told a story by their teacher (who had previously read the story to herself twice and was telling it to the children from memory) four out of five days per week for ten weeks, with a new story told each week, in addition to their usual classroom literacy practices. The story-reading group were read the same story from a book by their teacher, four out of five days per week for ten weeks, with a new story read each week, in addition to their usual classroom literacy practices. The comparison group continued with their usual classroom literacy practices. Usual classroom literacy practices consisted of the children receiving a literacy lesson once a day, as well as being read some stories by the teacher, usually on an ad hoc basis which varied a little between the different classes.

The storytelling and story-reading interventions were universal programmes delivered to all children in the class, irrespective of their oral and written language abilities and selfperception. This was done as children with any level of language skills, and those learning English as an additional language, could still benefit from receiving an intervention aimed at improving these skills, and oral and written language skills may help develop each other (Dockrell \& Connelly, 2009). The interventions were delivered in the children's classroom 
by the class teacher, at the same time each day, straight after the lunch-break. The stories took around 5-15 minutes to read or tell, varying slightly between each story.

All the stories used in the intervention came from the book 'The Puffin Book of Stories for Six-Year-Olds' edited by Wendy Cooling (Cooling, 1996). This book consists of 14 short stories, each written by a different author, from a range of cultural backgrounds and covering a range of topics. This book was selected for use in the interventions because the stories had all been identified as being suitable for this age group of children, and it was hoped that the diversity of stories would appeal to children from a range of social and cultural backgrounds, minimising any bias in children's interest in the stories or their ability to remember them.

The pre-test activities consisted of the teachers reading or telling the story 'The Tortoises' Picnic' to their class twice. Participants' oral language was then measured by asking them to retell the story they had just heard whilst recording this on a voice recorder, before transcribing. The transcriptions of participants' oral story retellings were analysed for: fluency, by counting the total number of words used; vocabulary, by counting the total number of different words used; and key points of the story, by counting how many of the points on the teacher's story prompt sheet (showing the main points of each story) were included in the child's retelling, as these measures of oral language ability have been used in previous research in this area (Isbell et al., 2004). Participants were also asked to write a retelling of the story for 15 minutes and their teachers marked these written story retellings using the Writing Assessment Measure (WAM; Dunsmuir et al., 2015). This involved their teacher giving a score of 0-4 for each of seven criteria relating to writing ability: handwriting, spelling, punctuation, sentence structure and grammar, vocabulary, organisation and overall structure, and ideas; $30 \%$ of these were then second marked by the first author to check interrater reliability. Participants all also completed the Early Attitudes Test - Revised (EAT-R; 
Frederickson \& Dunsmuir, 2001) which was used to measure their self-perception. The EAT$\mathrm{R}$ is a 20 question survey of self-perception in relation to the following sub-scales: reading, writing, maths, peer relations, self-esteem, and global self-perception. It was devised for children aged four to seven years and it is a downward extension of the Burnett Self Scale (Burnett, 1999). Examples of some items are: 'Can you do well at reading?', and 'Do you enjoy writing?' There are indications that the EAT-R is a reliable measure; moderate to strong Spearman's rank correlations were reported between the scores achieved by children on each of the EAT-R subscales between the first and second time they took the test (ranging from 0.46 for maths and 0.61 for writing) indicating satisfactory test re-test reliability (Clarke, Savage, Sethi \& Wright, 2002). The EAT-R was administered via a website. Questions were presented by a female voice in auditory format and four possible answers were provided (emphatic yes, moderately-stated yes, moderately-stated no, and emphatic no), each with an accompanying animated face which shook or nodded its head with the degree of vigour indicated by the auditory tone. Participants were required to point to the image that best matched their response to the question posed. Oral vocabulary was measured using the vocabulary subtest of the Wechsler Intelligence Scale for Children - Fourth UK Edition (WISC-IV UK; Wechsler, 2003). This involved participants being asked to define words of increasing complexity; the first author read aloud each question to each participant individually, the participant replied verbally, and the first author wrote down the participant's answer in the record booklet. The results of these pre-test activities provided baseline data to measure the children's oral and written language abilities and self-perception in each condition before they received the intervention.

At the end of the 10-week intervention, post-test activities were carried out: the teachers read or told the story 'How Trouble made the Monkey Eat Hot Peppers', which is a similar length to the pre-test story, twice, and the participants were then asked to write a 
retelling of the story, and to give an oral retelling of the story, recorded on a voice recorder, and then transcribed. Participants then repeated completion of the EAT-R. The results of these post-test activities provided data to see the children's oral and written language abilities and self-perception after they had received the intervention, and to find out whether there was any variation between the three intervention conditions. The vocabulary subtest of the WISCIV was not administered at post-test as it is recommended that a gap of at least six months is left between each administration in order to avoid practice effects (Wechsler, 2003).

Three months after the intervention was completed (in July 2016), follow-up assessments were carried out. Teachers read or told the story 'The Hodja and the Saucepan' twice; this is a similar length to, but slightly shorter than, the pre-test and post-test stories. Participants were asked to write a retelling of the story, and to give a verbal retelling of the story, recorded on a voice recorder, and then transcribed. Participants completed the EAT-R again; they also completed the vocabulary subtest of the WISC-IV, as it was six months since the pre-test administration of this. The results of these follow-up activities provided data to evaluate whether there had been any enduring change to the children's oral and written language abilities and self-perception as a result of the interventions.

This study received ethical approval. An opt-out parent consent form was sent to the parents or carers of every child in the participating classes before the start of the intervention, and usual research ethical guidelines were followed.

Training. Teachers were randomly allocated to intervention conditions. Prior to beginning the intervention, participating teachers attended an hour-long training session, where they were given a manual summarizing implementation, that they could refer to throughout the intervention, and the book of stories (Cooling, 1996), to ensure standardization of delivery across all teachers. Teachers allocated to the storytelling intervention condition 
were also given prompt sheets providing the key elements of each story to refer to when telling the story, if necessary.

During the training session, the teachers were shown a video of a former teacher reading a story, fulfilling the key features of both the storybook reading intervention and the storytelling intervention. These were two lively videos demonstrating how to read and tell the stories, highlighting the emphasis, animation and use of gestures and intonation required in the storytelling condition, and contrasting this with the engaging but less animated reading of the story from the book in the story-reading condition. These videos gave teachers a clear idea of how to deliver the intervention they had been allocated to deliver, and allowed them to ask any questions about the delivery of the storytelling and story-reading interventions. This process encouraged consistency of the teachers' own story delivery as they were guided by the video demonstrations. Teachers were consulted about whether the interventions and the pre- and post-test activities seemed feasible for them to carry out, and all agreed that they were.

The teachers carried out the pre-test measures during the day before the interventions began, and during the first few days of the interventions. All the teachers were female and they had all been teaching for between 5 and 15 years.

A fidelity checklist was designed for this study to assess the delivery of the storytelling intervention and the story-reading intervention in the six participating schools, as no fidelity checklists used in similar research could be found. This checklist drew on Dane and Schneider's (1998) and Durlak and Dupre's (2008) implementation dimensions: fidelity, dosage, quality, participant responsiveness, programme differentiation, monitoring of control/comparison conditions, programme reach, and adaptation (Dane \& Schneider, 1998; Durlak \& Dupre, 2008), combined with Bishop et al.'s (2014) measures of fidelity. The 
fidelity checks consisted of a teacher being video-recorded delivering the intervention, with checklist completion occurring whilst the first author viewed the video recording after the lesson had taken place. Teachers were each observed roughly four times during the ten week intervention, across the storytelling and story-reading conditions; during all observations teachers were found to have adhered to all implementation dimensions outlined on the checklist, suggesting $100 \%$ fidelity for sessions observed. As instructed, teachers in the storytelling intervention condition used the interactive features of storytelling to a greater extent (regular eye-contact with children, gestures and actions, characters' voices, a range of facial expressions, and varying volume and/or pitch of voice) when telling the stories (average rating of 28.6 out of the 36 for use of these features) than those in the story-reading condition (average rating of 17.3 out of 36 for use of these features). Teachers in the intervention groups completed a short survey at the end of the intervention about how they had found implementing it.

\section{Results}

Mixed Analyses of Variance (ANOVAs) were conducted in order to compare participants' scores on each of the measures between the storytelling group, the story-reading group, and the comparison group at pre-test, post-test, and follow-up, and to see if there were any significant differences between these scores (see table 1 for p-values and table 2 for effect sizes for each measure). Preliminary checks were carried out to make sure that there was no violation of the assumptions of normality, and homogeneity of variance; skewness and kurtosis were within acceptable levels for all dependent variables except the EAT-R subscales which were all negatively skewed. Tukey's post-hoc comparisons were conducted when an ANOVA showed a significant main effect in order to identify between which groups the 
significant difference in scores occurred. Bonferroni corrections were applied to protect against Type I error, which can be increased when running multiple ANOVAs.

ANOVAs showed that there was no significant difference in participants' oral fluency scores during their oral story retellings between the different groups at pre-test $(F(2,174)=$ $1.744, p=0.178)$, but there was a significant difference at post-test $(F(2,185)=16.428, p<$ $0.001)$, and at follow-up $(F(2,161)=12.493, p<0.001)$. Post-hoc comparisons showed that at post-test there was a significant difference in the oral fluency scores between the storytelling group $(M=237.18, S D=79.765)$ and story-reading group $(M=141.05, S D=$ 81.430; $p<0.001)$, and a significant difference between the storytelling group $(M=237.18$, $S D=79.765)$ and comparison group $(M=171.14, S D=95.715 ; p<0.001)$. There was no significant difference in oral fluency scores between the story-reading group and comparison group ( $p=0.732$ ). At follow-up there was a significant difference in oral fluency scores between the storytelling group $(M=133.33, S D=52.652)$ and story-reading group $(M=$ 87.45, $S D=41.297 ; p<0.001)$, and a significant difference between the storytelling group $(M$ $=133.33, S D=52.652)$ and comparison group $(\mathrm{M}=95.54, \mathrm{SD}=55.428 ; p=0.001)$. There was no significant difference in oral fluency scores between the story-reading group and comparison group $(p=0.892)$.

ANOVAs showed that there was no significant difference in participants' oral vocabulary scores during their oral story retellings between the different groups at pre-test $(F(2,175)=1.048, p=0.353)$, but there was a significant difference at post-test $(F(2,185)=$ $10.300, p<0.001)$, and at follow-up $(F(2,161)=15.882, p<0.001)$. Post-hoc comparisons showed that at post-test there was a significant difference in oral vocabulary scores between the storytelling group $(M=98.94, S D=28.116)$ and story-reading group $(M=68.82, S D=$ $34.672 ; p<0.001)$, and a significant difference between the storytelling group $(M=98.94, S D$ $=28.116)$ and comparison group $(M=80.23, S D=40.642 ; p=0.002)$. There was no 
significant difference in the oral vocabulary scores between the story-reading group and comparison group $(p=0.835)$. At follow-up there was a significant difference in oral vocabulary scores between the storytelling group $(M=57.34, S D=18.134)$ and story-reading group $(M=40.95, S D=15.040 ; p<0.001)$, and a significant difference between the storytelling group $(M=57.34, S D=18.134)$ and comparison group $(M=40.94, S D=20.796$; $p<0.001)$. There was no significant difference in oral vocabulary scores between the storyreading group and comparison group $(p=0.890)$.

ANOVAs showed that there was no significant difference in participants' WISC-IV vocabulary subtest scores between the different groups at pre-test $(F(2,184)=0.702, p=$ 0.497), but there was a significant difference in scores between the different groups at followup $(F(2,186)=3.535, p=0.031)$ (the WISC-IV was only carried out at pre-test and follow-up to avoid practice effects). Post-hoc comparisons showed that at follow-up there was a significant difference in WISC-IV vocabulary subtest scores between the story-reading group $(M=9.01, S D=3.062)$ and comparison group $(M=7.80, S D=2.941 ; p=0.045)$. There was no significant difference in WISC-IV vocabulary subtest scores between the storytelling group and comparison group $(p=0.883)$, or between the storytelling group and story-reading group $(p=0.110)$.

ANOVAs showed that there were no significant differences found between intervention groups at pre-test, post-test, or follow-up for key points of stories included in oral retellings, written retellings of stories scored by teachers using the WAM, or on any measures within the EAT-R.

The results of the short survey completed by the six teachers in the intervention groups about how they had found implementing the interventions showed that teachers in the storytelling condition noticed improvements to children's oral and written language skills, whereas teachers in the story-reading condition did not notice any changes to these areas other 
than expected progress over time. Also, teachers in the storytelling and story-reading conditions noted similar difficulties in running the intervention, but teachers in the storytelling condition reported being likely to continue using more elements of the intervention in the future than those in the story-reading condition.

\section{Discussion}

Children in the storytelling group produced significantly longer oral retellings than children in the story-reading group and comparison group; this accords with the finding of Isbell et al.'s (2004) study that children in the storytelling group had greater mean lengths of utterances than those in the story-reading group (Isbell et al., 2004).

Also, the story-reading intervention group scored significantly better on the vocabulary subtest of the WISC-IV at post-test than the comparison group, and the storytelling group used significantly wider vocabulary in their oral story retellings than both the other groups. These results show the potential benefit of a regular story intervention of reading or telling on children's developing vocabulary; this is congruent with research showing an improvement in children's vocabulary as a result of exposure to regular storytelling (Maguire, 1985), or story-reading (Baker et al., 2013).

However, the storytelling intervention did not lead to significant improvements to children's written recounts of the stories they had heard. This may be due to the fact that writing is a different medium to oral presentation, whereas oral story retelling was the same medium as the intervention and therefore more likely to improve due to direct knowledge and skill transfer as a result of the intervention. This is consistent with Isbell et al.'s (2004) study, which reported that the storytelling group were better at retelling stories orally than the storyreading group, but the story-reading group were better at creating a story using a wordless 
picture book than the storytelling group - each group improving in the medium of the intervention received (Isbell et al., 2004). Similar findings have been reported for interventions in related areas. For example, Lonigan et al. (2013) randomly assigned children to groups to receive either meaning-focused reading interventions (dialogic reading or shared reading) or code-focused reading interventions (focussing on phonological awareness, letter knowledge, or both), or a control group (Lonigan et al., 2013). They found that the interventions led to significant improvements in the children's reading skills, but only in those domains targeted by the intervention they received (Lonigan et al., 2013). In addition, Fisher and Frey's (2017) study looked at middle school teachers' use of strategies to develop the oral language skills of students in their classes who were learning English as an additional language. They found that the students' language skills improved in the specific areas which had been targeted through the teaching strategies teachers had implemented, such as use of grammar improving after small group needs-based grammar instruction and reading abilities improving after teaching involving exposure to a wide range of text types and topics (Fisher \& Frey, 2017). This suggests that the medium of the intervention affected which skills improved. This implies that children are most likely to learn the skills they have witnessed in others during the delivery of the intervention, rather than related abilities such as writing stories, which they have not witnessed during the intervention. This suggests that a story writing intervention would be likely to lead to improvements in children's written retellings of stories, but this was not seen in the present study as the interventions only exposed children to story-reading or storytelling.

Alternatively, an explanation for the fact that the only significant change as a result of the intervention was found in children's oral language is that the study involved a short intervention of only ten weeks, and linguistic concepts acquired in oral language often take about a year longer to be seen in written language (Loban, 1976). This may be because 
children's knowledge of oral language contributes to and stimulates the development of their written language (Dockrell \& Connelly, 2009; Dockrell et al., 2007; Dunsmuir \& Blatchford, 2004), and the writing process involves using 'talk knowledge' (Myhill, 2009), and is therefore partly dependent on children's oral language abilities. Moreover, all children who do not have any special educational needs develop the ability to speak at least one language without any formal teaching (Crain \& Lillo-Martin, 1999), whereas writing is an artificial task which requires formal teaching and takes a lot longer to develop. This suggests that if the present intervention had lasted a year or more, these same significant improvements seen in children's oral language as a result of the storytelling intervention might have also been seen in their written language and their self-description and self-evaluation ratings of their writing abilities measured by the EAT-R, due to their improved oral language abilities leading to improvements in their written language abilities (Dockrell \& Connelly, 2009). Therefore, the findings of the present study may reinforce Dockrell and Connelly's (2009) theory, which provides the theoretical framework for this study, suggesting that children's oral language may inform their written language, so improvements to children's written language may be seen some time after improvements to their oral language.

In contrast, the lack of any significant differences between intervention groups on ratings of their peer relations, self-esteem, or overall perception of their abilities at school as rated on the EAT-R might suggest that storytelling does not impact on aspects of children's self-perception at school. However, this may have been due to the short-term nature of the intervention; the fact that improvements were seen to children's oral language may highlight the power of storytelling to affect change in children's oral language, whereas other changes may take longer to develop to a measurable degree. Perhaps if a measure of enjoyment of the intervention, or a measure of self-perception in relation to children's ability to retell or rewrite stories, had been taken then the storytelling group might have scored higher than the story- 
reading group and comparison group as this would be more directly related to the intervention than their self-perception of other abilities at school. Alternatively, an effect might have been detected if an indirect measure of enjoyment had been taken, such as amount of fidgeting, as a possible indicator of engagement and absorption during delivery of the intervention. For example, Myers (1990) found that children fidgeted less when they were told stories than when they were read stories from books (Myers, 1990); this finding might have been replicated in the present study if fidgeting had been measured.

Strengths of current study. There are a number of strengths of this study. Firstly, there was a low level of attrition during the study: 209 participants were recruited for the research and 194 participants continued until the end (a 7\% attrition rate); this ensured that the intervention groups were of a good size and remained similar in composition throughout the intervention. Secondly, the inclusion of a comparison group in this study, who continued with their usual literacy practices, ensured that any improvements in measures at post-test and follow-up were not simply due to the children being older or having learnt more in other areas of school, but were likely to be a direct result of the intervention. Thirdly, the fact that the design included a three-month follow-up enabled the researchers to explore the longer-term impact of the interventions, providing further evidence of the effectiveness of the storytelling intervention in improving children's oral language.

Limitations of current study. There are also some limitations of the present study. Firstly, participants' oral and written retellings were scored in different ways - oral retellings were scored by calculating the total number of words used, total number of different words used, and total number of key points of the original story included in the retelling, whereas the written retellings were scored using the WAM which is dependent on adult judgements about the quality of aspects of writing. It was not possible in the timescale of this research to transcribe all of the children's written story retellings and score them in the same way as the 
oral story retellings. If this had been done, then these two measures of language skills would be more comparable and there may have been some significant differences found between the children's fluency and vocabulary in their story rewritings in the different intervention groups, as was found for the oral retellings.

Secondly, ideally the participants would have been randomly assigned to intervention conditions and would all have received the intervention from the same person in order to ensure that the groups were equally matched and that there were minimal differences in intervention delivery. Even though fidelity checks were conducted, they were carried out on just $10 \%$ of the intervention sessions delivered, and may not have detected all variation in implementation.

Thirdly, teachers in the storytelling condition were instructed to be animated and use gestures and varied intonation while telling the stories; whereas, the teachers in the storyreading condition were instructed to be engaging, but less animated. This difference in instruction may have contributed to the significant difference between the two groups in children's improved oral language. If teachers in both conditions were instructed to deliver the stories in exactly the same way, but with one group reading and one group telling the stories, there may have been less difference between the children's oral language in the storyreading and the storytelling intervention conditions.

Further research. As children get older, they tend to focus less on the secretarial elements of the writing process, and between seven and 11 years old they become more aware of compositional elements of writing (Wray, 1994). Therefore, it would be interesting to see the effect of this storytelling intervention on the written story retellings of older children who are more proficient at written composition, allowing them to write more and use a wider range of words in 15 minutes. This older population might be more likely to show a demonstrable 
impact of storytelling on written language, particularly if this is measured in the same way as the oral story retellings were measured in the current study, by counting the number of words written, number of different words written, and number of key points of the original story included in the rewriting.

Moreover, all children have to learn to adapt their oral language to fit with the level of formality of their speech and the social context they are in. However, this process is often more difficult for children who do not speak Standard English or those who are learning English as an additional language, and their oral language proficiency may mask difficulties with written language (Perera, 1984). Therefore the large EAL population in the present study may have influenced the response to the intervention on children's written language. Conducting the present study with children who are mostly learning English as their first language might show larger improvements in their written story retellings than those seen in the current study, as their spoken and written language skills might be more consistent. This would be interesting to explore as it could suggest that this intervention might be more effective in improving children's written language in schools with a population of majority native English speakers.

In addition, further research could explore in more depth the experiences of the children and teachers during the storytelling and story-reading interventions, to extend this study which briefly explored teachers' views through the implementer feedback survey. For example, research could look at views such as: whether children and teachers enjoy the process of implementing and receiving the intervention; whether children feel more engaged when being told stories compared to when being read stories from books; whether teachers and children look forward to the sessions; and whether elements of the sessions drift into other aspects of school life, for example into the children's games and drawings. 
Recommendations and implications. This study showed that telling stories to six and seven year old children led to improvements in their oral vocabulary, and oral fluency during story retellings. These findings suggest that storytelling would be beneficial for primary school teachers to use regularly with their classes to develop children's oral language, aiding comprehension of stories. Improved oral language skills may also lead to children contributing more to class discussions, giving longer answers to teachers' questions, experiencing greater enjoyment of and engagement with language and literature which may reduce broader problems associated with language difficulties, such as classroom disruption and behavioral difficulties.

\section{References}

Applebee, A. (1978). The child's concept of story. Chicago, IL: University of Chicago Press. Archibald, J.-A., (2008). Indigenous storywork: Educating the heart, mind, body and spirit. Vancouver, British Columbia: The University of British Columbia Press.

Baker, S. K., Santoro, L. E., Chard, D. J., Fien, H., Park, Y., \& Otterstedt, J. (2013). An evaluation of an explicit read aloud intervention taught in whole-classroom formats in first grade. The Elementary School Journal, 113(3), 331-358.

Barnes, D. (1990). Oral language and learning. In S. Hynds \& D. L. Rubin (Eds.), Perspectives of talking and learning (pp. 41-54). USA: National Council of Teachers of English.

Bishop, D. C., Pankratz, M. M., Hansen, W. B., Albritton, J., Albritton, L., \& Strack, J. (2014). Measuring fidelity and adaptation: Reliability of an instrument for school-based prevention programs. Evaluation \& the Health Professions, 37(2), 231-257. 
Bereiter, C., \& Scardamalia, M. (1982). From conversation to composition: The role of instruction in a developmental process. In Glaser, R. (Ed.), Advances in Instructional Psychology Volume 2 (pp. 1-64). Hillsdale, NJ: Lawrence Erlbaum Associates.

Berninger, V., Mizokawa, D., Bragg, R., Cartwright, A., \& Yates, C. (1994). Intraindividual differences in levels of written language. Reading and Writing Quarterly, 10, 259-275.

Berninger, V. (2000). Development of language by hand and its connections to language by ear, mouth, and eye. Topics in Language Disorders, 20, 65-84.

Bishop, D. V. M., \& Clarkson, B. (2003). Written language as a window into residual language deficits: A study of children with persistent and residual speech and language impairments. Cortex, 39(2), 215-237.

Blum, R. W. (2005). A case for school connectedness. The Adolescent Learner, 62(7), 16-20.

Bolin, I. (2006). Growing up in a culture of respect: Child rearing in highland Peru. Austin, Texas: The University of Texas Press.

Bourdin, B., \& Fayol, M. (2000). Is graphic activity cognitively costly? A developmental approach. Reading and Writing: An Interdisciplinary Journal, 13, 183-196.

Brabham, E. G., \& Lynch-Brown, C. (2002). Effects of teachers' reading-aloud styles on vocabulary acquisition and comprehension of students in the early elementary grades. Journal of Educational Psychology, 94(3), 465-473.

Brett, A., Rothlein, L., \& Hurley, M. (1996). Vocabulary acquisition from listening to stories and explanations of target words. The Elementary School Journal, 96(4), 415-422.

Bruner, J. S. (1986). Actual minds, possible worlds. Cambridge, Massachusetts: Harvard University Press. 
Burnett, P. C. (1999). Burnett self scale (BSS). In N. Frederickson, \& R.J. Camerson (Eds) Psychology in education portfolio (pp 8-10). NFER-Nelson: London.

Chafe, W. L. (1982). Integration and involvement in speaking, writing, and oral literature. In D. Tannen (Ed.), Spoken and written language: Exploring orality and literacy (pp.35-54). Norwood, NJ: Able.

Clarke, A., Savage, R., Sethi, S., \& Wright, R. (2002). Measuring young children's selfperceptions (unpublished master's dissertation). University College London, London.

Cohen, J. (1988). Statistical power analysis for the behavioral sciences (2nd Ed.). Hillsdale, NJ: Erlbaum.

Cooling, W. (1996). The puffin book of stories for six-year-olds. London: Penguin Group.

Corbett, P. (2007). The bumper book of storytelling into writing. London: Clown Publishing.

Cragg, L., \& Nation, K. (2006). Exploring written narrative in children with poor reading comprehension. Educational Psychology: An International Journal of Experimental Educational Psychology, 26(1), 55-72.

Crain, S. \& Lillo-Martin, D. (1999). An introduction to linguistic theory and language acquisition. US: Wiley-Blackwell.

Cummins, J. (1991). Interdependence of first- and second-language proficiency in bilingual children. In E. Bialystok (Ed.), Language processing in bilingual children (pp. 70-89). Cambridge: Cambridge University Press.

Czerniewska, P. (1992). Learning about writing. Oxford: Blackwell. 
Dane, A. V., \& Schneider, B. H. (1998). Program integrity in primary and early secondary prevention: Are implementation effects out of control? Clinical Psychology Review, 18(1), 23-45.

Department for Education (DfE). (2008). Talk for writing. Nottingham: DCSF Publications.

Dockrell, J. E., Lindsay, G., Connolly, V. \& Mackie, C. (2007). Constraints in the production of written text in children with specific language impairments. Exceptional Children, 73(2), 147-164.

Dunsmuir, S. \& Blatchford, P. (2004). Predictors of writing competence in 4- to 7-year-old children. British Journal of Educational Psychology, 74(3), 461-483.

Dunsmuir, S., Kyriacou, M., Batuwitage, S., Hinson, E., Ingram, V., \& O’Sullivan, S. (2015). An evaluation of the writing assessment measure (WAM) for children's narrative writing. Assessing Writing, 23, 1-18.

Durlak, J. A., \& DuPre, E. P. (2008). Implementation matters: A review of research on the influence of implementation on program outcomes and the factors affecting implementation. American journal of community psychology, 41, 327-350.

Egan, K. (1995). Narrative and learning: A voyage of implications. In H. McEwan \& K. Egan (Eds), Narrative in teaching, learning, and research (pp. 116-125). New York: Teachers College Press.

Egan, K. (1997). The educated mind: How cognitive tools shape our understanding. Chicago, IL: Chicago University Press.

Epstein, S.-A., \& Phillips, J. (2009). Storytelling skills of children with specific language impairment. Child Language Teaching and Therapy, 25(3), 285-300. 
Farrell, C. H., \& Nessell, D. D. (1982). The effects of storytelling: An ancient art for modern classrooms (Report No. ISBN-0-936434-04-X). San Francisco, CA.

Favat, A. F. (1977). Child and tale: The origins of interest. Urbana, IL: National Council of Teachers of English.

Fien, H., Santoro, L., Baker, S. K., Park, Y., Chard, D. J., Williams, S., \& Haria, P. (2011). Enhancing teacher read alouds with small-group vocabulary instruction for students with low vocabulary in first-grade classrooms. School Psychology Review, 40(2), 307-318.

Fisher, D., \& Frey, N. (2017). Developing oral language skills in middle school English learners. Reading \& Writing Quarterly, 1-18.

Flower, L. (1979). Writer-based prose: A cognitive basis for problems in writing. College English, 41(1), 19-37.

Frederickson, N., \& Dunsmuir, S. (2001). Early attitudes test (revised). London: Educational Psychology Publishing, University College London.

Freiberg, H. J. (1989). Turning around at-risk schools through consistency of management. Journal of Negro Education, 58, 372-382.

Gallets, M. (2005). Storytelling and story reading: A Comparison of the effects on children's memory and story comprehension. (unpublished master's dissertation). East Tennessee State University.

Gibb, N. (2016, February 3). The importance of storytelling. Retrieved from https://www.gov.uk/government/speeches/the-importance-of-storytelling

Gillam, R., \& Johnston, J. (1992). Spoken and written language relationships in language learning impaired and normally achieving school-age children. Journal of Speech and Hearing Research, 35, 1303-1315. 
Hidi, S., \& Hildyard, A. (1983). The comparison of oral and written productions in two discourse types. Discourse Processes, 6(2), 91-105.

Isbell, R., Sobol, J., Lindauer, L., \& Lowrance, A. (2004). The effects of storytelling and story reading on the oral language complexity and story comprehension of young children. Early Childhood Education Journal, 32(3), 157-163.

Kory, J. \& Breazeal, C. (2014). Storytelling with robots: Learning companions for preschool children's language development, presented at the 23rd IEEE international symposium on robot and human interactive communication, Edinburgh, 2014. New Jersey: Institute of Electrical and Electronics Engineers (IEEE).

King, K. A., Vidourek, R. A., Davis, B., \& McClellan, W. (2002). Increasing self-esteem and school connectedness through a multidimensional mentoring program. Journal of School Health, 72, 7, 294-299.

Kroskrity, P. V. (2009). Narrative reproductions: Ideologies of storytelling, authoritative words and generic regimentation in the village of Tewa. Journal of Linguistic Anthropology. 19, 40-56.

Loban, W. (1976). Language development: Kindergarten through grade twelve (research report 18). Urbana, IL: National Council of Teachers of English.

Lonigan, C. J., Purpura, D. J., Wilson, S. B., Walker, P. M., \& Clancy-Menchetti, J. (2013). Evaluating the components of an emergent literacy intervention for preschool children at risk for reading difficulties. Journal of Experimental Child Psychology, 114, 111-130.

Maguire, J. (1985). Creative storytelling: Choosing, inventing, and sharing tales for children. New York: The Phillip Lief Group, Inc. 
Maynard, K. L., Pullen, P. C., \& Coyne, M. D. (2010). Teaching vocabulary to first-grade students through repeated shared storybook reading: A Comparison of rich and basic instruction to incidental exposure. Literacy Research and Instruction, 49, 209-242.

Mello, R. (2001). The power of storytelling: How oral narrative influences children's relationships in classrooms. International Journal of Education and the Arts, 2(1), 1-15.

McNeely, C. A., Nonnemaker, J. M., \& Blum, R. W. (2002). Promoting school connectedness: Evidence from the national longitudinal study of adolescent health. Journal of School Health, 72(4), 138-146.

Moore, W., Hammond, L., \& Fetherston, T. (2014). Strengthening vocabulary for literacy: An analysis of the use of explicit instruction techniques to improve word learning from story book read-alouds. Australian Journal of Learning Difficulties, 19(2), 153-172.

Myers, P. (1990). Stories from print. Language Arts, 67(8), 824-831.

Myhill, D. A. (2009). From talking to writing: Linguistic development in writing. British Journal of Educational Psychology Monograph Series, 11(6), 27-44.

O'Donnell, R. C. (1974) Syntactic differences between speech and writing. American Speech, 49(1/2) 102-110.

Palmer, B. C., Harshbarger, S. J., \& Koch, C. A. (2001). Storytelling as a constructivist model for developing language and literacy. Journal of Poetry Therapy, 14(4), 199-212.

Perera, K. (1984). Children's writing and reading: Analysing classroom language. Oxford: Blackwell.

Perera, K. (1986). Grammatical differentiation between speech and writing in children aged 812. In A. Wilkinson (Ed.), The writing of writing (pp.90-108). OUP: Milton Keynes. 
Perera, K. (1987). Understanding language. Sheffield: NAAE.

Pinker, S. (2007). The language instinct: How the mind creates language. London: Harper Perennial Modern Classics.

Polkinghorne, D. E. (1991). Narrative and self-concept. Journal of Narrative and Life History, 1(2), 135-153.

Pranis, K. (2001). Building justice on a foundation of democracy, caring and mutual responsibility (manuscript held by Minnesota Department of Corrections).

Pullen, P. C., Tuckwiller, E. D., Konold, T. R., Maynard, K. L., \& Coyne, M. D. (2010). A tiered intervention model for early vocabulary instruction: The effects of tiered instruction for young students at risk for reading disability. Learning Disabilities Research \& Practice, 25(3), 110-123.

Puranik, C., Lombardino, L., \& Altman, L. (2007). Writing through retellings: An exploratory study of language impaired and dyslexic populations. Reading and Writing, 20, 251-272.

Resnick, M. D., Harris, K. M., \& Shew, M. (1997). Protecting adolescents from harm: Findings from the National Longitudinal Study on Adolescent Health. Journal of the American Medical Association, 278(10), 823-832.

Semel, E., Wiig, E. H., \& Secord, W. A. (2003). Clinical evaluations of language fundamentals 4th edition: Examiner's manual. San Antonio, TX: Harcourt Assessment, Inc.

Shanahan, T. (2006). Relations among oral language, reading and writing development. In C. MacArthur, S. Graham, \& J. Fitzgerald (Eds.), Handbook of writing research (pp. 171-183). New York: Guilford Press.

Shavelson, R. J., Hubner, J. J., \& Stanton, G. C. (1976). Self-concept: Validation of construct interpretations. Review of Educational Research, 46(3), 407-441. 
Trostle, S., \& Hicks, S. J. (1998). The effects of storytelling versus story reading on comprehension and vocabulary knowledge of British primary school children. Reading Improvement, 35(3), 127-136.

Wechsler, D. (2003). Wechsler intelligence scale for children - Fourth UK edition (WISC$\left.I V^{u k}\right)$. London: Harcourt Assessment.

Table 1

Results of ANOVAs showing the P-Values of the Main Effects of Time (Pre-test, Post-test and Follow-up), Intervention Group, and the Interaction between these Variables

\begin{tabular}{|c|c|c|c|}
\hline Dependent Variables & $\begin{array}{l}\text { Main effect of } \\
\text { time }\end{array}$ & $\begin{array}{l}\text { Main effect of } \\
\text { intervention group }\end{array}$ & $\begin{array}{l}\text { Interaction between } \\
\text { time and group }\end{array}$ \\
\hline Oral fluency & $<0.001 * *$ & $<0.001 * *$ & $<0.001 * *$ \\
\hline Oral vocabulary & $<0.001 * *$ & $0.001 * *$ & $0.001 * *$ \\
\hline Oral key points of story & $<0.001 * *$ & $0.014^{*}$ & 0.199 \\
\hline $\begin{array}{l}\text { WISC vocabulary } \\
\text { subtest score }\end{array}$ & $<0.001 * *$ & 0.164 & 0.027 \\
\hline Written retellings & $<0.001 * *$ & $0.018^{*}$ & 0.354 \\
\hline $\begin{array}{l}\text { EAT-R Writing self- } \\
\text { description scores }\end{array}$ & 0.430 & 0.376 & 0.325 \\
\hline $\begin{array}{l}\text { EAT-R writing self- } \\
\text { evaluation scores }\end{array}$ & $0.030 *$ & 0.558 & 0.451 \\
\hline EAT-R total scores & 0.762 & 0.460 & 0.135 \\
\hline $\begin{array}{l}\text { EAT-R peer relations } \\
\text { scores }\end{array}$ & $0.013 *$ & 0.622 & 0.328 \\
\hline $\begin{array}{l}\text { EAT-R self-esteem } \\
\text { scores }\end{array}$ & 0.661 & 0.889 & 0.227 \\
\hline
\end{tabular}


Table 2

Results of ANOVAs showing the Effect Size (Partial $\eta 2)$ of the Main Effects of Time (Pre-test, Post-test and Follow-up), Intervention Group, and the Interaction between these Variables

\begin{tabular}{llll}
\hline Dependent Variables & $\begin{array}{l}\text { Main effect of } \\
\text { time }\end{array}$ & $\begin{array}{l}\text { Main effect of } \\
\text { intervention group }\end{array}$ & $\begin{array}{l}\text { Interaction between } \\
\text { time and group }\end{array}$ \\
\hline Oral fluency & $0.418^{* *}$ & $0.129^{*}$ & $0.163^{* *}$ \\
Oral vocabulary & $0.543^{* *}$ & $0.098^{*}$ & $0.099^{*}$ \\
Oral key points of story & $0.588^{* *}$ & $0.060^{*}$ & 0.022 \\
$\begin{array}{l}\text { WISC vocabulary } \\
\text { subtest score }\end{array}$ & $0.105^{*}$ & 0.020 & 0.041 \\
$\begin{array}{l}\text { Written retellings } \\
\text { EAT-R Writing self- } \\
\text { description scores }\end{array}$ & $0.225^{* *}$ & 0.046 & 0.013 \\
$\begin{array}{l}\text { EAT-R writing self- } \\
\text { evaluation scores }\end{array}$ & 0.031 & 0.017 & 0.020 \\
$\begin{array}{l}\text { EAT-R total scores } \\
\text { EAT-R peer relations }\end{array}$ & 0.002 & 0.014 & 0.010 \\
scores & 0.039 & 0.014 & 0.025 \\
$\begin{array}{l}\text { EAT-R self-esteem } \\
\text { scores }\end{array}$ & 0.004 & 0.008 & 0.020 \\
\hline
\end{tabular}

*Medium effect size (> 0.06; Cohen, 1988)

**Large effect size (> 0.14; Cohen, 1988) 